\title{
Germinação e desenvolvimento in vitro de orquídea epífita do Cerrado ${ }^{(1)}$
}

\author{
CARLOS DE SOUSA SILVA(2), LEILA GARCÊS DE ARAÚJO(2), KELLEN CRISTHINA INÁCIO SOUSA(2*), \\ DANIELA MOTA SILVA ${ }^{(3)}$, SÉRGIO TADEU SIBOV ${ }^{(3)}$ E PAULO ROBERTO FARIA $^{(3)}$
}

\begin{abstract}
RESUMO
Orquídeas são plantas muito procuradas em função da beleza e diversidade, de cores e formatos, de suas flores. Visando obter uniformidade, vigor e sanidade das mudas bem como produzir grandes quantidades para a comercialização usa-se a propagação in vitro. $\mathrm{O}$ objetivo deste trabalho foi avaliar a geminação e o desenvolvimento in vitro de Cyrtopodium saintlegerianum para aclimatação. Os meios MS, MS1르, Knudson C modificado e Simplificado foram testados na germinação das sementes. No desenvolvimento das plântulas foram avaliados os meios Knudson C modificado, MS e MS modificado (adição de auxina e citocinina). Os meios MS, MS1 12 e Knudson C modificado promoveram germinação acima de $80 \%$ após sete dias. Contudo, no meio Simplificado as sementes germinaram após trinta dias. Nas duas avaliações, trinta e sessenta dias após o início do experimento, o meio Knudson C modificado foi eficiente para as variáveis observadas demonstrando seu potencial uso na germinação e desenvolvimento dessa espécie.
\end{abstract}

Palavras-chave: Cyrtopodium saintlegerianum Rchb. f., Orchidaceae, meios de cultivo, reguladores de crescimento.

\begin{abstract}
In vitro germination and development of the Cerrado epiphytic orchid

Orchids are very popular plants due to the beauty and diversity, of colors and shapes, of their flowers. In order to obtain uniformity, vigor and sanity of the seedlings as well as to produce large quantities for the commercialization is used the in vitro propagation. The objective of this study was to evaluate the germination and in vitro development of Cyrtopodium saintlegerianum for acclimatization. The MS, MS1 12 , Knudson C modified and Simplified media were tested on seed germination. In the development of the seedlings were evaluated Knudson C modified, MS and MS modified (addition of auxin and cytokinin). The MS, MS 12 and Knudson C modified media promoted germination above $80 \%$ after seven days. However, in the Simplified medium the seeds germinate after thirty days. In the two evaluations, thirty and sixty days after the beginning of the experiment, the Knudson $\mathrm{C}$ modified medium was efficient for the observed variables demonstrating their potential use in germination and development of this species.
\end{abstract}

Keywords: Cyrtopodium saintlegerianum Rchb. f., Orchidaceae, culture medium, growth regulators.

\section{INTRODUÇ̃̃O}

A família Orchidaceae é uma das mais diversas e representativas do Cerrado (BATISTA et al., 2005). Das cinquenta espécies do gênero Cyrtopodium Rchb. que são registradas no Continente Americano cerca de trinta, dentre terrestres e epífitas, ocorrem no Cerrado (BATISTA e BIANCHETTI, 2006; ROMERO-GONZÁLES et al., 2008).
Cyrtopodium saintlegerianum Rchb. f. é uma orquídea com pseudobulbos alongados e flores amarelas com manchas marrons. Pode ser encontrada como epífita nos estados de Goiás (Figura 1A), Mato Grosso, Distrito Federal, Minas Gerais e São Paulo (ROMERO-GONZÁLES et al., 2008; FERREIRA et al., 2010a); ou como terrestre em áreas mistas de mata e savana nos estados do Pará, Amazonas, Maranhão e Mato Grosso (BARROS et al., 2011; ZAPPI et al., 2015).

\footnotetext{
DOI: http://dx.doi.org/10.14295/oh.v23i1.923

(1) Recebido em 02/08/2016 e aceito em 21/02/2017

(2) Universidade Federal de Goiás, Instituto de Ciências Biológicas, Departamento de Genética, Laboratório de Genética de Microrganismos, GoiâniaGO, Brasil.*Autor para correspondência: bio.kcisbr@gmail.com

(3) Universidade Federal de Goiás, Instituto de Ciências Biológicas, Departamento de Genética, Laboratório de Cultura de Tecidos Vegetais, GoiâniaGO, Brasil
} 


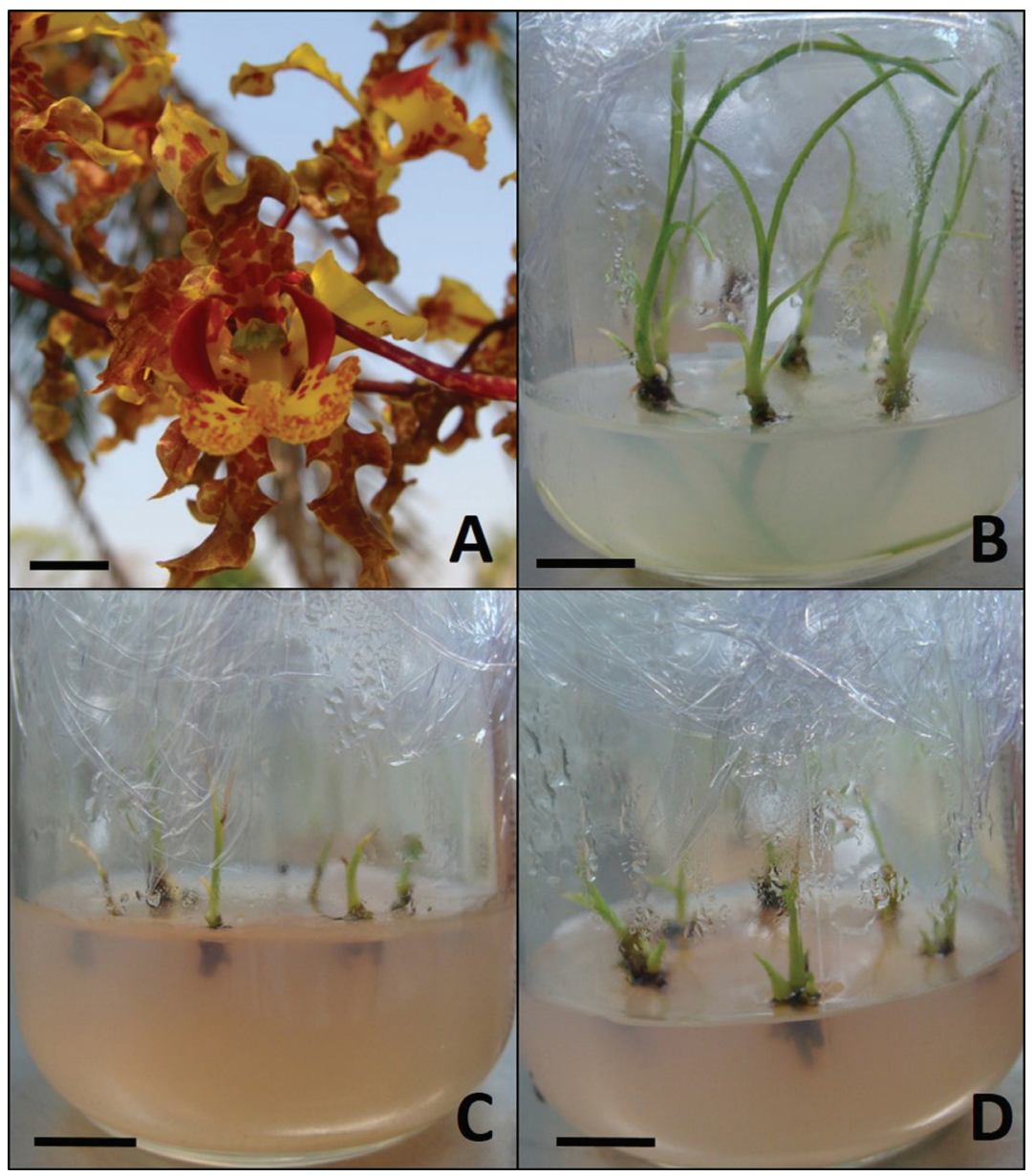

Figura 1. Aspecto geral da flor de Cyrtopodium saintlegerianum Rchb. f. epífita em área de Cerrado no estado de Goiás (A). Desenvolvimento de plântulas cultivadas em meio Knudson C modificado (B), em meio MS (C) e em meio MS modificado (D). (Barras: $1 \mathrm{~cm}$ ). (Figuras: Sousa, K. C. I. e Silva, C. S.).

Figure 1. General aspect of Cyrtopodium saintlegerianum Rchb. f. flower epiphyte in Cerrado area, state of Goiás (A). Development of plantlets in Knudson C modified medium (B), and MS medium (C) and MS modified medium (D). (Bars: $1 \mathrm{~cm}$ ). (Figures: Sousa, K. C. I. and Silva, C. S.).

O cultivo in vitro de orquídeas em meios nutritivos possibilita rapidez e uniformidade na obtenção de plântulas, enquanto que na natureza a taxa de germinação de sementes é baixa e o desenvolvimento das plântulas é lento (ARDITTI e KRIKORIAN, 1996; STEWART e KANE, 2006). Além disso, em habitat natural as orquídeas necessitam de associações micorrízicas para a obtenção de nutrientes tanto na germinação de sementes bem como na fase adulta (DEARNALEY et al., 2012). No cultivo in vitro de orquídeas os meios mais utilizados são o MS (MURASHIGE e SKOOG, 1962) e o Knudson (KNUDSON, 1922). Os constituintes e as quantidades de um meio de cultura são otimizados de acordo com as necessidades nutricionais das plantas. Como exemplo, o meio Knudson $\mathrm{C}$ que foi modificado visando o cultivo de orquídeas (ARDITTI, 1977). Em outros estudos também é observada a modificação nos meios ou por adição de hormônios comerciais ou por uso de polpas de frutas (BHADRA e HOSSAIN, 2003; PORNPIENPAKDEE et al., 2010; FAVETTA et al., 2014).
Meio Knudson C suplementado com 6-benzilaminopurina (BAP), ácido $\alpha$-naftalenoacético (ANA) e ácido giberélico $\left(\mathrm{GA}_{3}\right)$ para induzir brotações em protocormos de $C$. saintlegerianum foi testado. Observou-se que relação auxina-citocinina tem influência no aumento do número de brotações, mas que o uso de $\mathrm{GA}_{3}$ pode interferir negativamente na aclimatação e reintrodução de plântulas (RODRIGUES et al., 2015). Diante o exposto, o objetivo do presente estudo foi avaliar a germinação de sementes e o rápido desenvolvimento de plântulas de $C$. saintlegerianum em diferentes meios (in vitro) visando cultivo sustentável.

\section{MATERIAL E MÉTODOS}

Foram usadas sementes de uma cápsula de Cyrtopodium saintlegerianum com dez meses de maturação após fecundação cruzada em habitat natural. Na germinação os meios testados foram MS normal, MS com metade de macronutrientes (MS 1/2); Knudson C modificado por Arditti (1977) e meio Simplificado (Água de coco verde, 
Banana nanica e Adubo Foliar - Peter's ${ }^{\circledR}$ NPK 20-2020). Todos os meios foram acrescidos com $30 \mathrm{~g} \mathrm{~L}^{-1} \mathrm{de}$ sacarose e $7 \mathrm{~g} \mathrm{~L}^{-1}$ de ágar. $\mathrm{O} \mathrm{pH}$ dos meios foi ajustado para 5,7 $\pm 0,1$ antes da adição do ágar. Cada tratamento contendo 20 frascos com $30 \mathrm{~mL}$ de meio de cultura e $1 \mathrm{~g}$ de sementes. Os frascos foram mantidos sob temperatura de $24 \pm 2{ }^{\circ} \mathrm{C}$ com 2700 lux de luminosidade e fotoperíodo de 16 h. A cada sete dias foram avaliados os estádios de germinação e o desenvolvimento dos protocormos de acordo com a escala de notas de 0 a 5, a saber: 0 - embrião intacto; 1 - embrião intumescido e presença de rizoides (germinação); 2 - rompimento do tegumento que envolve o embrião; 3 - estabelecimento do protocormo e formação da protuberância foliar; 4 - surgimento da primeira folha; e 5 - alongamento da primeira folha e surgimento da segunda folha (STEWART e KANE, 2006).

Os protocormos (Estádio 5) provenientes da germinação nos meios MS, MS1/2 e Knudson C modificado foram utilizadas no ensaio de desenvolvimento in vitro. Foram testados três meios: Knudson $\mathrm{C}$ modificado, MS e MS modificado (com acrécimo de $4 \mathrm{mg} \mathrm{L}^{-1}$ de auxina e $1 \mathrm{mg} \mathrm{L} \mathrm{m}^{-1}$ de citocinina). A unidade experimental foi um frasco de vidro de $150 \mathrm{~mL}$, contendo $30 \mathrm{~mL}$ de meio e seis plântulas com $0,5 \mathrm{~cm}$ de altura. Os frascos foram acondicionados em sala de crescimento com temperatura de $24 \pm 2^{\circ} \mathrm{C}$ e fotoperíodo de $16 \mathrm{~h}$ com intensidade luminosa de 1800 lux. O delineamento experimental usado foi inteiramente casualizado (DIC) com três tratamentos e trinta repetições. Foram realizadas duas avaliações, após trinta e sessenta dias do início do experimento, das seguintes variáveis: o número de folhas, a altura da parte aérea $(\mathrm{cm})$, o número de brotações e o tamanho da maior raiz $(\mathrm{cm})$. Usou-se paquímetro analógico e as medições foram realizadas externamente, sem a retirada das plantas dos frascos. Os dados foram submetidos à análise de variância e as médias comparadas pelo teste Tukey (5\% de probabilidade) utilizando o Software R versão 2.11.0.

\section{RESULTADOS E DISCUSSÃO}

Após sete dias houve germinação de $80 \%$ (Estádio 2) nos meios MS, MS $1 / 2$ e Knudson C modificado. Nesses meios também foi observada a formação de protocormos (Estádio 3) quinze dias após o início do teste. Porém, no meio Simplificado observou-se o Estádio 2 somente trinta dias após a semeadura. Stewart e Kane (2006) testaram a germinação de Habenaria macroceratitis em diferentes meios de cultivo e obtiveram formação de protocormos após dezesseis dias nos meios MS normal e Knudson C. Por outro lado, na germinação de Baptistonia pubes (Lindl.) Chiron \& V.P. Castro foram testados os meios MS, MS1 $1 / 2$ e de Formulação Alternativa (à base de banana) e observou-se que o terceiro promoveu melhores porcentagens de germinação em relação aos demais (FERREIRA et al., 2010b).

Após trinta dias do início do ensaio observou-se o meio Knudson $\mathrm{C}$ modificado diferiu estatisticamente dos demais para o número de folhas, altura de plantas e tamanho da maior raiz. Entretanto, não diferiu do meio MS modificado para o número de brotações (Tabela 1). Após dias sessenta de cultivo, mesmo não diferindo estatisticamente do meio MS modificado para duas características avaliadas, observou-se que o meio Knudson $\mathrm{C}$ foi o mais eficiente em aumentar o número de folhas e brotações bem como o tamanho da parte aérea (Figura 1B-D, Tabela 1). Após sessenta dias, as raízes cresceram e se entrelaçaram de modo que não foi possível a avaliação do tamanho destas em nenhum dos meios estudados (Tabela 1).

Tabela 1. Influência dos meios de cultura no número de folhas, na altura da parte aérea, no número de brotações e no tamanho da maior raiz de Cyrtopodium saintlegerianum.

Table 1. Influence of culture media in the number of leaves, the shoot height, number of shoots and the size of the largest root of Cyrtopodium saintlegerianum.

\begin{tabular}{|c|c|c|c|c|}
\hline Meio & $N^{0}$ de folhas & $\begin{array}{l}\text { Altura da parte aérea } \\
\qquad(\mathrm{cm})\end{array}$ & $\mathbf{N}^{0}$ de brotações & $\begin{array}{l}\text { Tamanho da maior raiz } \\
\qquad(\mathrm{cm})\end{array}$ \\
\hline \multicolumn{5}{|c|}{ Avaliação após trinta dias } \\
\hline Knudson C & $4,30 a^{*}$ & $3,59 \mathrm{a}$ & $2,27 \mathrm{a}$ & $4,62 \mathrm{a}$ \\
\hline MS & $2,33 \mathrm{~b}$ & $1,48 \mathrm{~b}$ & $0,40 \mathrm{~b}$ & $0,65 \mathrm{~b}$ \\
\hline MS modificado & $2,33 \mathrm{~b}$ & $1,11 \mathrm{~b}$ & $2,20 \mathrm{a}$ & $0,53 \mathrm{~b}$ \\
\hline \multicolumn{5}{|c|}{ Avaliação após sessenta dias } \\
\hline Knudson C & $2,76 \mathrm{a}$ & $6,23 \mathrm{a}$ & $1,86 \mathrm{a}$ & - \\
\hline MS & $1,91 \mathrm{~b}$ & $2,08 \mathrm{~b}$ & $0,41 \mathrm{~b}$ & - \\
\hline MS modificado & $2,16 \mathrm{ab}$ & $1,13 \mathrm{~b}$ & $2,24 \mathrm{a}$ & - \\
\hline
\end{tabular}

*Médias seguidas pela mesma, na vertical, não diferem entre si pelo teste Tukey (nível de significância de 5\%). 
Em estudos testando o meio Knudson C com $200 \%$ de nutrientes com a adição de $2,5 \mathrm{mg} \mathrm{L}^{-1}$ de $\mathrm{GA}_{3}$ observouse aumento no número de folhas de Cattleya loggigesii. Maior número de brotações foi observado quando usada a quantidade normal (100\%) dos sais de Knudson C. Para o híbrido Hadrolaelia lobatta x Hadrolaelia purpurata verificou-se que o dobro da concentração (200\%) aumentou o número de folhas, mas o número de brotações foi maior quando usada a metade da concentração (50\%). Notou-se que não houve influência do $\mathrm{GA}_{3}$ no número de brotos, comprimento da parte aérea e na massa fresca das plântulas do híbrido (SOARES et al., 2009). Testando a influência de fitorreguladores de cultivo em uma espécie nativa (Laelia crispata [Thunb.] Garay) e um híbrido [(Laeliacattleya Culminant "Tuilerie" $x$ Laeliacattleya Sons Atout Rotunda) $x$ Bassolaeliacattleya Startifire Moon Beach], notouse que a primeira apresentou maior número de internós na presença de ANA e na ausência de BAP, e o segundo apresentou maior número de internós quando acrescido de ANA (SOARES et al., 2010). Diferentes concentrações de auxinas no meio MS proporcionaram efeito positivo no crescimento da parte aérea e na formação de brotações de Geodorum densiflorum (Lam.) Schltr. (BHADRA e HOSSAIN, 2003).

O acréscimo de citocinina, em diferentes concentrações, induziu brotações bem como promoveu o desenvolvimento de plântulas de Dendrobium sp. híbrido (PORNPIENPAKDEE et al., 2010). Meios suplementados com BAP e ANA influenciaram positivamente no número de brotações de $C$. saintlegerianum, mas a adição de $\mathrm{GA}_{3}$ não favoreceu na aclimatação destas plantas (RODRIGUES et al., 2015). No presente estudo, o meio MS acrescido de fitorreguladores proporcionou maior número de brotações, mas não diferiu estatisticamente do meio Knudson C. O meio Knudson $\mathrm{C}$ é menos dispendioso em sua composição, seu preparo é mais fácil comparando-se aos demais sendo, portanto, eficiente no desenvolvimento de $C$. saintlegerianum. Estudos posteriores poderão avaliar a taxa de sobrevivência destas plântulas quando aclimatadas em estufas ou jardins ou reintroduzidas em troncos de palmeiras em áreas de Cerrado.

\section{CONCLUSÃO}

O meio Knudson $\mathrm{C}$ é recomendado para o desenvolvimento inicial de Cyrtopodium saintlegerianum por proporcionar aumento na parte aérea, no número de folhas e no número de brotações.

\section{AGRADECIMENTOS}

Os autores agradecem à Fundação de Amparo à Pesquisa do Estado de Goiás (FAPEG) pelo suporte financeiro no desenvolvimento desta pesquisa.

\section{CONTRIBUIÇÃO DOS AUTORES}

CSS: realização dos experimentos em laboratório, revisão bibliográfica, análises estatísticas e redação do manuscrito; LGA: orientação nas análises estatísticas e correção do manuscrito; KCIS: revisão bibliográfica, análises estatísticas e redação do manuscrito; STS: supervisão dos experimentos em laboratório bem como a orientação nas análises estatísticas; DMS: suporte técnico/ teórico nos experimentos em laboratório, apoio nas análises estatísticas bem como na discussão dos resultados e correção do artigo; PRF: suporte técnico/teórico nos experimentos em laboratório e apoio na discussão dos resultados.

\section{REFERÊNCIAS}

ARDITTI, J. Clonal propagation of orchids by means of tissue culture: A manual. In: ARDITTI, J. Orchid Biology: Reviews and Perspectives. Ithaca, NY: Cornell University Press., p.203-293, 1977.

ARDITTI,J.; KRIKORIAN,A.D. Orchidmicropropagation: the path from laboratory to commercialization and an account of several unappreciated investigators. Botanical Journal of the Linnean Society, v.122, p.183-241, 1996.

BARROS, F.V.; RODRIGUES, V.T.; FRAGA, C.N.; PESSOA, E.M. Orchidaceae. In: Lista de Espécies da Flora do Brasil (Jardim Botânico do Rio de Janeiro). Disponível em: <http://floradobrasil.jbrj.gov.br/2011/ FB025908>. Acesso em: 20 de agosto de 2011.

BATISTA, J.A.N.; BIANCHETTI, L.B. A New Species of Cyrtopodium (Orchidaceae) from the Cerrado of Central Brazil. Novon, v.16, p.17-22, 2006.

BATISTA, J.A.N.; BIANCHETTI, L.B.; PELIZZARO, K.F. Orchidaceae da Reserva Ecológica do Guará, DF, Brasil. Acta Botanica Brasilica, v.19, p.221-232, 2005.

BHADRA, S.K.; HOSSAIN, M.M. In vitro Germination and Micropropagation of Geodorum densiflorum (Lam.) Schltr., an Endangered Orchid Species. Plant Tissue Culture, v.13, p.165-171, 2003.

DEARNALEY, J.D.W.; MARTOS, F.; SELOSSE, M.A. Orchid mycorrhizas: molecular ecology, physiology, evolution and conservation aspects. In: HOCK, B. (ed.) The Mycota IX: fungal associations, 2 ed., Springer: Berlin, p.207-230, 2012.

FAVETTA, V.; COLOMBO, R.C.; FARIA, R.T. Cultivo in vitro de Vanda tricolor Lindl. em meios de cultura simplificados. Revista de Ciências Agrárias, v.57, p.114$117,2014$.

FERREIRA, A.W.C.; LIMA, M.I.S.; PANSARIN, E.R. Orchidaceae na região central de São Paulo, Brasil. Rodriguésia, v.61, p.243-259, 2010a.

FERREIRA, A.W.C.; LIMA, M.I.S.; FARIA, R.T.; RIBEIRO, J.P.N.; CASALI, C.A. Propagação in vitro de Baptistonia pubes (Lindl.) Chiron \& Castro (Oncidium pubes Lindl.) (Orchidaceae). Acta Botanica Brasilica, v.24, p.636-639, 2010 b. 
KNUDSON, L. Nonsymbiotic Germination of Orchids Seeds. Botanical Gazette, v.73, p.1-25, 1922.

MURASHIGE, T.; SKOOG, F. A revised medium for rapid growth and bioassay with tobacco tissue culture. Physiologia Plantarum, v.15, p.473-497, 1962.

PORNPIENPAKDEE， P.; SINGHASURASAK, R.; CHAIYASAP, P.; PICHYANGKURA, R.; BUNJONGRAT, R.; CHADCHAWAN, S.; LIMPANAVECH, P.; MURASHIGE, T.; SKOOG, F. Improving the micropropagation efficiency of hybrid Dendrobium orchids with chitosan. A revised medium for rapid growth and bioassay with tobacco tissue culture. Scientia Horticulturae, v.124, p. 490-499, 2011.

RODRIGUES, L.A.; PAIVA NETO, V.B.; BOARETTO, A.G.; OLIVEIRA, J.F.; TORREZAN, M.A.; LIMA, S.F.; OTONI, W.C. In vitro propagation of Cyrtopodium saintlegerianum Rchb. f. (ORCHIDACEAE), a native orchid of the Brazilian savannah. Crop Breeding and Applied Biotechnology, v.15, p.10-17, 2015.

ROMERO-GONZÁLEZ, G.A.; BATISTA, J.A.N.; BIANCHETTI, L.B. A synopsis of the genus Cyrtopodium (Catasetinae: ORCHIDACEAE). Harvard Papers in Botany, v.13, p.189-206, 2008.
SOARES, J.D.R.; ARAÚJO, A.G.; PASQUAL, M.; RODRIGUES, F.A.; ASSIS, A.A. Concentrações de sais do meio Knudson e de ácido giberélico no crescimento in vitro de plântulas de orquídeas. Ciência Rural, v.39, p. 772-777, 2009.

SOARES, J.D.R.; PASQUAL, M.; RODRIGUES, F.A.; ARAÚJO, A.G. Estiolamento e luz artificial no cultivo in vitro de orquídeas nativa e híbrida. Ciência Rural, v.40, p.1941-1947, 2010.

STEWART, S.L.; KANE, M. E. Asymbiotic seed germination and in vitro seedling development of Habenaria macroceratitis (Orchidaceae), a rare Florida terrestrial orchid. Plant Cell Tissue and Organ Culture, v.86, p.147-158, 2006.

ZAPPI, D.C.; RANZATO FILARDI, F.L.; LEITMAN, P.; SOUZA, V.C.; WALTER, B.M.T.; PIRANI, J.R.; MORIM, M.P.; QUEIROZ, L.P.; CAVALCANTI, T.B.; MANSANO, V.F.; FORZZA, R.C. Growing knowledge: an overview of Seed Plant diversity in Brazil. Rodriguésia, v.66, p.1085$1113,2015$. 